\title{
Sons urbanos e suas escutas através do cinema
}

\section{Fernando Morais da Costa}

\section{Resumo}

Este trabalho pretende analisar as possibilidades de representação dos ambientes sonoros urbanos pelo cinema. Para tanto, nos detemos, em uma primeira seção, nas chamadas "sinfonias de cidades", filmes produzidos na passagem do cinema mudo para o cinema sonoro. Em um segundo momento, fazemos uma ponte com o cinema contemporâneo, analisando filmes nos quais a representação do espaço de determinadas cidades é central para as respectivas tramas. Em todos os filmes analisados, sendo-nos aqui indiferente a época em que foram produzidos, nos interessa pensar a parte sonora da representação, ao mesmo tempo em que podemos pensar como as escutas de tais filmes podem provocar no espectador uma reflexão sobre o modo com o qual ele se relaciona com os sons que 0 circundam no cotidiano urbano.

\section{Palavras-chave}

Som. Cinema. Cidade. Sons ambientes. Escuta.

Fernando Morais da Costa | fmorais29@terra.com.br Doutor em Comunicação pela Universidade Federal Fluminense (UFF). Professor adjunto do Departamento de Cinema e Vídeo e do Programa de Pós-Graduação em Comunicação da UFF.

\section{Introdução}

\section{This town's so strange \\ They built it to change \\ And while we're sleeping \\ all the streets, they rearrange \\ Arcade Fire - Suburban War}

Em artigo recente, fizemos uma crítica à

prevalência recente de termo paisagem sonora na análise de som no cinema, embora 0 termo, a soundscape do canadense Murray Schafer, não se relacione originalmente a análise de filmes. ${ }^{1}$ Entretanto, nos parece que a construção da ambientação sonora que faz parte da construção de cada espaço representado dentro de um filme, ou seja, a presença do que se convencionou chamar em cinema de sons ambientes, poderia ser 0 que há de próximo à ideia de que cada lugar pode ter uma assinatura sonora representável. Para pensar sobre isso, tomamos como objeto desta análise filmes que tenham por objetivo representar mais diretamente 0 cotidiano de 
determinadas cidades, ou seja, filmes nos quais as próprias cidades tenham papel fundamental.

Já comentamos em outras ocasiões, mais brevemente ou menos, filmes como alemão $O$ céu de Lisboa, dirigido por Win Wenders, o uruguaio Ruído, dirigido por Marcelo Bertalmío. Por hora, podemos nos deter sobre algumas das chamadas "sinfonias de cidades", da passagem do dito cinema mudo para 0 sonoro. ${ }^{2}$

Como sinfonias de cidades entende-se um grupo de filmes, feitos em contextos de produção distintos, mas próximos quanto à época de suas filmagens e lançamentos, do qual são exemplos: Berlim, sinfonia de uma metrópole, (1927), Um homem com uma câmera (1929), São Paulo, a sinfonia da metrópole (1929), Rien que les heures (1926). Neste artigo, comentaremos, dos citados acima, as relações entre sons e imagens de Berlim, sinfonia de uma metrópole, além de acrescentarmos outros três filmes que, embora menos comentados, trazem representações de cidades que podem facilmente permitir sua inclusão no grupo das "sinfonias". São eles Entuziazm, o filme de Vertov posterior ao mais conhecido Um homem com uma câmera, Melodia do mundo, filme de Walter Ruttmann da mesma forma posterior à mais conhecida sinfonia de imagens e sons sobre Berlim ${ }^{3} \mathrm{e}$ a mais tardia produção inglesa The City.

\section{Sons vindos de Berlim, da Rússia, de Londres}

Berlim, sinfonia de uma metrópole é um filme ainda pertencente ao período entendido como mudo, já em seu final naquele ano de 1927, com a peculiaridade, comum à época, de já ter música composta especificamente para as suas imagens, para ser sincronizada na exibição. Ou seja, trata-se um filme já de passagem do mudo para 0 sonoro, com relações seguras e pré-estabelecidas entre sons, na forma de música, e imagens.

A música de Edmund Meisel descreve a intenção de produzir complementaridade com as imagens desde 0 início do filme, quando, ao vermos o mar, ouvimos uma melodia cuja sinuosidade procura emular o vai e vem das ondas. ${ }^{4}$ Da mesma forma, quando já estamos

Quando dizemos "dito" período mudo, estamos nos filiando a correntes de pesquisadores sobre o som no cinema que entendem tal período como um longo laboratório de inúmeras tentativas de sonorização. A culminância do cinema sonoro, comumente datada de 1927, graças aos primeiros êxitos comerciais de filmes falados nos EUA seria, assim, não um momento histórico isolado, mas 0 resultado de um longo processo de união de sons e imagens, que tem a mesma data do início do cinema. Esse modo de entender os primeiros trinta anos do cinema pode ser encontrado, por exemplo, nos trabalhos do norte-americano Rick Altman (2004).

Antes de realizar as duas sinfonias de cidades, o cineasta alemão Walter Ruttmann já se tornara reconhecido pelos curtasmetragens experimentais realizados na década de 1920, como a série Opus, composta por quatro filmes, realizados entre 1921 e 1924. Dando continuidade ao interesse por retratar cidades, Ruttmann dirigiria ainda, na década de 1930, os menos conhecidos documentários Stuttgart (1935) e Düsseldorf (1936). 
em terra, mas não na cidade, o tempo da música que serve de trilha sonora para 0 trem que vemos acelera-se e divide-se de forma a simbolizar os supostos sons da máquina, inclusive com os metais da orquestra emulando seu apito. No mesmo sentido, poderíamos comentar sobre os solenes e grandiosos tempos largos com os quais as imagens do centro da cidade são apresentadas, ou crescendo que se une à abertura dos portões das fábricas. Tais representações por música de ações presentes nas imagens, que não tiveram os ruídos correspondentes a elas gravados, seguem pelo filme, como é o caso do apito de um funcionário da companhia ferroviária, ou de uma máquina de socar em meio a uma obra. Já próximo do fim do filme, no quinto ato, como o filme é dividido, música e imagem desenvolvem uma relação ainda mais próxima. Vemos um maestro. Vemos quando ele bate a batuta na partitura, o que demonstra para os espectadores que ele começará a reger. Até aqui, uma pausa acompanha providencialmente tais imagens. Inicia-se a regência nas imagens, tem inicio a música, e entendemos que o maestro rege, do fosso, a música de um número de vaudeville. Fica patente, aos menos para os olhos e ouvidos deste espectador contemporâneo, a falta de verossimilhança entre 0 que a orquestra nos faz ouvir e 0 que vemos as dançarinas executar. Ainda assim, a música invadira as imagens. Passara a ser justificada no espaço da ação, o que até então não acontecera.
Dois anos após Berlim, sinfonia de uma metrópole, Ruttmann lança Melodia do mundo. As cartelas iniciais explicam que neste filme, ao invés da ode a uma cidade específica, 0 intuito é fazer "um apelo à fraternidade", uma homenagem às semelhanças de todos os povos, em especial aos trabalhadores de países diversos. Em determinado momento, uma cartela descreve uma espécie de estatuto das funções dos sons, ao nos informar que "o acompanhamento sonoro e musical especialmente composto para 0 filme sublinha $\mathrm{e}$ reforça a melodia visual". Aqui deve ser explicado que no intervalo entre 1927 e 1929 a gravação de som para cinema dá vários de seus passos definitivos, e Melodia do mundo, ao contrário do filme anterior, conta com uma série de ruídos e com algumas vozes unidas às imagens, e não apenas com música. A empresa alemã TobisKlangfilm, que sonorizaria o início do cinema sonoro alemão e expandiria seus serviços para as vizinhas, França e Dinamarca, e mesmo para 0 incipiente cinema sonoro português, firmando-se como uma das alternativas europeias ao domínio mundial das tecnologias norte-americanas de gravação de som para cinema, seria a responsável pela gravação dos sons utilizados em Melodia do mundo. Assim, à música original, desta vez a cargo de Wolfgang Zeller, somam-se sons de navios que vemos na tela, de martelos utilizados por operários, de correntes sendo puxadas, de apitos de fábrica, e demais manifestações sonoras que simbolizem 0 trabalho nas grandes cidades. 
Neste sentido, Melodia do mundo é um filme exemplar dos passos que estavam sendo dados em direção às formas que seriam concretizadas em breve pelo cinema sonoro. Ainda há, é evidente, uma presença maciça da música, mas ruídos e falas já se fazem ouvir. Vale ressaltar a edição ritmada de alguns ruídos, o caso mais claro sendo os martelos na obra, o que simula com sons provenientes do espaço onde ocorre a ação uma estrutura musical. Michel Chion comenta a recorrência desse efeito nos primeiros anos do cinema sonoro, e batiza tal fenômeno de "efeito X", adaptando nomenclatura da música concreta de Pierre Schaeffer, que naquele contexto descrevia exatamente o procedimento de dotar séries de ruídos de ritmo claro (CHION, 2009, p. 42).

Entuziazm, de 1931, é a primeira experiência de Vertov com som no cinema. ${ }^{5}$ Se Um homem com uma câmera tornara-se célebre por sua representação de Leningrado/São Petersburgo, e continha música para ser sincronizada com as imagens, assim como os dois filmes de Ruttmann analisados, Entuziazm é uma espécie de reedição da representação urbana, agora já com os sons da cidade gravados. A representação cinematográfica do cotidiano citadino em volta do rio Don, no sul da Rússia fronteiriço com a Ucrânia, naquele início de década de 1931, transformou-se em uma das primeiras experiências sonoras do cinema russo. A norte-americana Lucy Fischer descreve 0 uso de som do filme como uma grande colagem sonora que é, ao mesmo tempo, uma tentativa radical de quebrar, para 0 espectador, a ilusão naturalista comum ao som no cinema (FISCHER, 1985, p. 251). Fischer, uma expoente da teoria feminista no cinema, sugere uma bem humorada hipótese sobre Entuziasm, ao dizer que tal filme, imediatamente posterior a Um homem com uma câmera, poderia se chamar "Uma mulher com fones de ouvido". Tal conexão esclareceria, em uma espécie de dupla vinculação, o sucesso do primeiro, em detrimento da pouca divulgação do segundo: da mesma forma que a câmera teria preponderância, na teoria do cinema, sobre os aparatos sonoros, também a figura do homem seria mais comumente analisada que a da mulher. Trata-se de uma hipótese ao mesmo tempo em defesa do papel da mulher e do som.

Fischer se refere ao início do filme. Após as cartelas iniciais, acompanhadas da primeira das muitas marchas militares que ouviremos no decorrer da projeção, vemos uma mulher, uma telefonista, portando os citados fones de ouvido, e cabeando sinais que automaticamente ouvimos. Em um jogo de identificação que torna evidente que compartilhamos o ponto de escuta ${ }^{6}$

Quando dizemos "a primeira experiência de Vertov com som no cinema", fazemos uma alusão ao fato de 0 cineasta tão conhecido pelos manifestos que definiriam, durante a década de 1920, o autointitulado "cine-olho" (kinoglaz), ter, bastante tempo antes, em 1917, criado o chamado Laboratório do ouvido, que tinha entre seus intuitos gravar sons urbanos e dotá-los de cunho narrativo.

Como definido por Michel Chion, em correspondência a seu primo mais famoso dentro da teoria cinematográfica, o plano ponto de vista. No Brasil, o ponto de escuta já foi a base da análise, por exemplo, do trabalho de Suzana Reck Miranda (2007), ao analisar a obra do canadense François Girard. 
daquela personagem, nós ouvimos o que ela ouve.

Partilhamos com ela o que sai de seus fones de ouvido. 0 que ouvimos é uma estação de rádio de Leningrado. 0 locutor anuncia que ouviremos uma "sinfonia donbassa", ou seja, uma sinfonia composta pelos sons da região do rio Don. $\mathrm{Na}$ prática, é um exercício refinado de metalinguagem: ouviremos pelo rádio, e pelos ouvidos da personagem, o som do filme a que assistimos. 0 que se segue não é menos complexo: surge nas imagens um maestro preparando-se para iniciar a regência. E 0 que ele se põe a reger, seguindo 0 raciocínio da sequência anterior, é a trilha sonora do filme. Vemos, pelos gestos do regente, que ele comanda inclusive as demais manifestações sonoras que surgem, para além da música. Quando ele faz um sinal para que os sinos das igrejas entrem na trilha sonora, temos a primeira dica de que embora a presença da música seja maciça, os sons das cidades e as vozes de seus habitantes não tardam a surgir. Na verdade, se não esquecermos no decorrer do filme essa figura do maestro que está colocado no início para reger o que ouvimos, podemos entender que a "música" do filme é uma grande junção de elementos musicais em si com demais sons do cotidiano urbano daquela região. Como exemplos de sons do cotidiano, temos os próprios sinos, uma parada militar, chaminés de fábricas, gritos de multidões, sons das minas de carvão, de toda a maquinaria necessária para a extração mineral, dos trens que carregam o produto do trabalho.

Sobre as condições de trabalho dos mineradores durante a implantação do Plano de Cinco Anos stalinista, temos uma surpreendente, para a época, gravação de som direto ao ar livre, através da qual ouvimos um carvoeiro explicar o quanto os trabalhadores estavam sendo forçados a produzir. Lucy Fischer explica que Vertov testava, em Entuziazm, a primeira tecnologia de gravação de som portátil de patente russa, que intentava solucionar, a partir do tamanho reduzido dos gravadores, a difícil tarefa de gravar sons fora de estúdios, o que, de resto, seria uma espécie de nó tecnológico para o cinema até a virada da década de 1950 para $1960 .{ }^{7}$ Outros momentos de falas gravadas ao ar livre são os cantos de trabalho das mulheres na colheita e um discurso inflamado para os camponeses. 0 que queremos ressaltar é que tais tentativas exitosas de Vertov de gravar as falas dos personagens nas locações demorariam ainda, devido às dificuldades em se conseguir resultados satisfatórios com gravadores portáteis, cerca de três décadas para serem usuais no cinema.

Há ainda, no filme de Vertov, a voz ocasional de um narrador, o que estabelece outro espaço para o uso

Fischer informa que tais gravadores portáteis russos vinham sendo testados desde 1929 nas ruas de Moscou. Vertov assumira, com um grupo de técnicos, a tentativa de adaptar 0 aparato às suas filmagens, fazendo testes de gravação em Leningrado, na Ucrânia, e logo após partindo para a região do rio Don. 0 contexto russo reflete demais tentativas, espalhadas pelo mundo afora, de realizar, naqueles anos, a gravação de som direto para cinema em sincronia com as imagens. Destacam-se, nesse cenário, as patentes norte-americanas, como o Vitaphone, o Movietone, o Photofone, os aparelhos da alemã Tobis-Klang Film, já citada, e algumas patentes brasileiras, como o Sincrocinex do produtor Luís de Barros. 
da voz, diverso do espaço da ação tomado pelas falas de quem aparece enquadrado pela câmera. É por esta voz de um narrador que temos as informações mais diretas sobre 0 que vemos nas imagens, embora sua fala apareça, de alguma forma, entrecortada, descontínua, o que a transforma em mais um exemplo da montagem anti-naturalista de Vertov. Ainda assim, a mensagem é clara quando o ouvimos dizer: "aconteceu em Donbassa, durante 0 Plano de Cinco Anos, em 1930", ou mesmo quando diz: "acabou 0 carvão".

Sobre uma série de recursos utilizados no filme para atingir 0 dito antinaturalismo, no intuito maior de tornar 0 espectador consciente da manipulação de sons necessária para chegarse ao produto final da escuta, Lucy Fischer elenca procedimentos aferíveis em Entuziazm, tais como: superposições sonoras, reversão temporal dos sons, cortes sonoros abruptos, contrastes tonais, falta de correspondência entre a distância dos sons para o microfone e a distância entre os objetos filmados e a câmera, metáforas sonoras, entre outras. Não cabe aqui a explicação de cada uma dessas técnicas, mas resta, dito brevemente, a noção de que se trata de um filme que complexifica as relações entre sons e imagens tantas vezes tidas como naturais pelo espectador. Nesse sentido, Entuziazm aponta, em 1931, de forma mais aguda que os filmes anteriores citados neste trabalho, para uma potencial complexificação do ato de ouvir que 0 cinema poderia descrever no decorrer do século XX.

The City é uma produção da britânica General Post Office Film Unit sobre a cidade de Londres, realizada em 1939. Assim, é posterior à passagem do cinema mudo para o sonoro, período no qual se enquadram os filmes analisados até este momento, mas traz em sua trilha sonora a marca da escola de documentários inglesa da década de 1930, para a qual a produtora ligada aos correios tem papel central. No lugar dos ruídos da cidade, uma mixagem quase completamente composta pela união de música e da voz de um narrador onisciente. A narração em primeira pessoa é evidente desde a primeira frase ouvida: "Esta é Londres, minha cidade natal". ${ }^{8}$ Há ainda uma segunda voz, também de um especialista, um historiador que vemos em seu local de trabalho. É a partir da trama entre essas duas vozes que teremos todas as informações verbais sobre a cidade, à medida que vemos o centro, as chaminés das fábricas, os subúrbios com as casas construídas à beira da linha do trem, o comércio naval no Tamisa, as torres das igrejas, o funcionamento interno dos correios. Com a ausência da gravação dos sons ambientes da cidade, ao invés da representação sonora de seus ruídos, temos a 
centralidade da voz de um narrador que explica tudo o que vemos, e de um personagem que, de dentro do espaço da ação, nos oferece também por palavras demais dados sobre a vida na urbe.

\section{Sons contemporâneos vindos de Tóquio, da Suíça, da América Latina}

Fazendo uma imensa elipse, e passando a pensar no cinema contemporâneo a mesma representação sonora das cidades, um filme como a produção catalã passada no Japão Map of the sounds of Tokyo ${ }^{9}$ usa 0 artifício, como Win Wenders fizera, na década de 1990, em $O$ céu de Lisboa, de ter como narrador um personagem técnico de som para tornar central a representação de determinados sons cotidianos da capital japonesa. Antes mesmo que partilhemos do ponto de escuta do personagem que trabalha com a gravação de sons, o que primeiro ouvimos dos espaços no quais se passam as ações é 0 burburinho em japonês e em inglês da reunião de negócios entre orientais e ocidentais. Em determinado momento dessa sequência, acontece o que Michel Chion (1994, p. 132) chama de "suspensão". Passamos a não ouvir os sons das ações, a partir da hora em que um personagem confidencia algo ao ouvido de outro. Com a queda, não justificada espacialmente, do som ambiente, o espectador é levado a entender que algo se quebrou na representação, e que tal quebra significa narrativamente um momento chave.
Trata-se da morte da filha do personagem que ouve, saberemos depois.

Ainda no início do filme, entra em cena Ryu, personagem que passaremos a acompanhar. Em várias cenas, a vemos com seus fones de ouvido, e o modo como a música é inserida em tais passagens faz parecer que ouvimos o que ela ouve; que, de forma análoga à impressão deixada pela telefonista do filme de Vertov, partilhamos do que é proveniente dos seus fones de ouvido. Isso acontece pelo fato dos pontos de entrada das músicas coincidirem exatamente com os momentos em que vemos os fones de ouvido em sua cabeça. A relação estabelecida entre 0 início dos sons e a primeira visão do aparato de escuta presente nas imagens faz 0 espectador, arriscamos dizer, desejar que tal música também esteja sendo ouvida pela personagem, o que geraria a identificação. Quando surgir o personagem técnico de som, também ouviremos pelos seus ouvidos, mediados pelos fones, embora nessas situações não haja espaço para a dúvida. Tratase de uma representação mais clara do ponto de escuta. É deste mesmo personagem a voz do narrador que, por vezes, passa a ser central para que 0 espectador entenda a trama. É ele quem fala, sempre a respeito da Ryu que conhecera, quando diz, por exemplo: "Não há dia em que eu não me recorde da respiração de Ryu". É o papel narrativo central da voz em um filme que preza tanto a representação dos ruídos. Sobre essa 
interface entre o que há no filme de verbal e o que há da presença de sons não-verbais do cotidiano, tal voz narra ainda sua própria admiração por determinados ruídos, como é o caso dos sons produzidos pelo ato de sorver 0 caldo do lamen, som que, de fato, ouvimos durante o filme repetidas vezes.

Mais sons de ações que ouvimos de forma destacada são aqueles produzidos ao cortar-se 0 peixe (o trabalho diurno de Ryu), espremer limões, calçar e descalçar sapatos, o som da água que cai no ato de lavar as lápides, 0 som das balas sendo colocadas no revólver. Destaque-se que a précondição para que se ouçam tais sons, ínfimos em suas intensidades, com clareza deve sempre ser a construção meticulosa de um ambiente silencioso. Não se poderia ouvir a representação de tais sons na tela se fosse de outra forma. Assim, 0 filme que faz ouvir pequenos ruídos cotidianos é, ao mesmo tempo, um filme que cria ambientes silenciosos nos quais pequenos sons se possam fazer ouvir. A própria voz do narrador-técnico de som ressalta certos momentos em que tais condições estão presentes, como ocorre na explicação verbal da especificidade do silêncio de um cemitério no verão, onde Ryu e o narrador de encontram para lavar as lápides dos assassinados.

Quanto à música presente em Map of the sounds of Tokyo, podemos citar a presença ritmos latinos, embora sejam tais canções cantadas em japonês; 0 destaque para uma canção da banda inglesa Antony and the Johnsons, One Dove; a referência constante de um dos personagens a Enjoy the silence, sucesso do grupo oitentista Depeche Mode. Assim, como tem sido recorrente em um certo cinema oriental contemporâneo, embora estejamos falando de uma produção catalã filmada no Japão, a música representa o que Denílson Lopes descreveu como uma paisagem transcultural, quando a trilha sonora tem papel importante em forjar um modelo de representação que foge dos limites das fronteiras nacionais (LOPES, 2003).

Caso instigante de representação de personagens que convivem com a mudança do ambiente sonoro ao qual estavam acostumados está em Home, produção suíça dirigida por Ursula Meier. Em frente à casa situada em uma até então silenciosa zona rural há uma estrada pouco utilizada. Vem do rádio a notícia de que o trânsito pesado de outra rodovia será desviado para ali. Em pouco tempo, o som ambiente rural será substituído pelos ruídos de todos os automóveis, dos caminhões. $\mathrm{Ou}$, diríamos ainda, submerge frente à intensidade maior do novo som ambiente. As janelas fechadas, 0 rádio ligado alto pela mãe, 0 heavy metal que toca nos fones de ouvido da filha, tudo passa a servir de refúgio do som ambiente tão mais intenso que 0 anterior. Entre a audição da notícia de que 0 trânsito está para ser aberto e a efetiva primeira passagem de um carro, há a construção silenciosa do suspense em que a família se encontra, até que 0 advento do tráfego pesado de fato confirme 0 caos aguardado. 0 subsequente esforço de isolar a casa, forrando 
as paredes com lã de vidro, cimentando janelas, até a clausura quase total será, por certo tempo, vitorioso, o que resulta, para nós, espectadores, em um filme novamente silencioso, pouco intenso na construção dos sons ambientes. Entretanto, o isolamento que não é só acústico, mas também da luminosidade e do contato com os ambientes externos no geral, tornar-se-á insuportável, e os personagens resolvem destruir o esquema de clausura que eles próprios haviam construído, rendendo-se à inexorabilidade da convivência com a nova situação sonora.

É-nos útil para pensar a representação das cidades por filmes recentes a análise de Angela Prysthon no artigo Metrópoles latino-americanas no cinema contemporâneo. Prysthon comenta o papel do cinema em representar as metrópoles latinas, com seus "modelos de uma urbanidade periférica e alternativa", a partir das adaptações locais dos parâmetros europeus, tendo como referência a tese de Beatriz Sarlo (1988 apud PRYSTHON, 2006, p. 255), especificamente sobre a Buenos Aires dos anos 1920 e 1930. Prysthon comenta que, uma vez cumprido o objetivo primeiro de quaisquer imagens e sons de cidades reproduzidos pelos filmes, qual seja, levar 0 espectador a aceitar como real o ficcional, uma vez que a ação pareça se passar em lugar reconhecível, a representação das grandes cidades latino-americanas pelo cinema atual serviria para revelar, de imediato, "uma urbanidade híbrida, periférica e tão peculiarmente cosmopolita" (PRYSTHON, 2006, p. 256). 0 papel ativo e complexo do cinema em retratar tais cidades torna-se claro ao concordarmos que "as cidades visíveis no cinema latino-americano contemporâneo não são necessariamente um reflexo do real, não correspondem a simulacros exatos do real, mas muitas vezes transformam o real, modificam o real" (PRYSTHON, 2006, p. 259). Para Prysthon, há ainda, na produção contemporânea uma espécie de divisão entre os filmes que procuram representar uma "fantasia" de cidade, na qual problemas urbanos enfrentados pela população em seu cotidiano não aparecem, e as produções que têm como objetivo denunciar exatamente tais problemas. No caso do primeiro grupo, Prysthon nota que "não são Buenos Aires, Santiago, Cidade do México, Rio de Janeiro que estão realmente em jogo nessas representações, mas as imagens dessas cidades que convêm às expectativas médias de uma idealização urbana" (PRYSTHON, 2006, p. 261).

Como exemplos de filmes cujas imagens e sons tragam para a tela tais questões relativas às cidades com as quais os personagens se relacionam, Prysthon elenca, entre outros, os argentinos Pizza, birra y faso e Esperando el mesías, o mexicano Temporada de patos, 0 uruguaio Whisky, o também argentino Valentín, o brasileiro Madame Satã. Sobre os dois últimos, em diálogo com a análise de Prysthon, diríamos que os sons dos filmes propõem indagações que nos interessam: em Valentin, a partir da proposta da recriação da Buenos Aires do fim dos anos 1960, e do papel central para tal recriação dos figurinos, da direção de arte e mesmo, 
como citado por Prysthon, da música pop que tocava na época, o que dizer dos demais sons que não a música? Se parece certo pensar no papel da música dentro da reconstrução para 0 cinema de determinada época, podemos também pensar no papel dos demais elementos sonoros presentes em um filme? Há como dizer que as vozes, os sotaques, os modos de falar, poderiam contribuir para que o espectador possa imergir no tempo recriado pelo filme? Pode-se supor que os ruídos e os sons ambientes a serem inseridos têm função semelhante? Sobre a relação entre música e som ambiente, o próprio Madame Satã citado por Ângela deixa transparecer um possível resposta: os sambas e marchinhas que ouvimos ao fundo por tantas vezes durante o filme são parte central da recriação da Lapa da década de 1930. Em um exercício de sutileza narrativa, as músicas que ouvimos, muitas vezes sob 0 volume maior dos diálogos, informam para 0 espectador quais sons podem ajudar a criar uma representação de espaço e tempo verossímeis. ${ }^{10}$

\section{Considerações e questionamentos finais}

0 pensamento sobre tais representações sonoras de cidades no cinema formata, então, os questionamentos centrais, não necessariamente passíveis de resposta, deste trabalho: há sons que possam ser entendidos como específicos da cada cidade, de cada ambiente dentro da pluralidade das cidades? É possível dizer hoje que as grandes cidades contêm manifestações sonoras peculiares? Há, por exemplo, sons cariocas? Nos parece que, com relação à música que toca nas ruas, poder-se-ia responder afirmativamente tais perguntas de forma mais direta. Pode-se sempre dizer que em determinada cidade, em determinadas regiões de cada cidade, ouve-se bastante certo gênero musical. Uma fictícia resposta análoga possivelmente daria conta da fala, dos sotaques. Mas aqui nos interessam particularmente os ruídos, os sons ambientes de cada lugar. Quanto a eles, o quanto carregariam particularidades de cada espaço no qual se manifestam? Há, como hipótese na obra de Murray Schafer, a suposição de que os sons das grandes cidades cada vez mais se tornariam uniformes, dada a presença das mesmas máquinas, dos mesmos motores, em metrópoles diversas mundo afora (SCHAFER, 1997). Em que medida posso dizer que são próprios do Rio de Janeiro os sons que gravo na cidade? Quando gravo o trânsito da Rua das Laranjeiras, a mistura de sons urbanos e de natureza do Aterro do Flamengo, quando gravo a Baía da Guanabara ouvida da Praia do Flamengo, o que nesses sons carrega a assinatura de cada lugar? Todas as gravações, feitas em casa, das primeiras palavras do meu filho têm, e terão, o trânsito da Rua das Laranjeiras como fundo. 
Em que medida o convívio com esses sons é específico do lugar onde moro? 0 quanto influem os parâmetros técnicos de gravação? Quando ouço a chuva gravada da janela da sala sob uma taxa de amostragem de som digital de $96 \mathrm{Khz}$, a 24 bits, a chuva me parece irreal, ou melhor dizendo, hiper-real.

Recentemente, a professora Carolyn Birdsall, do Departamento de Comunicação da Universidade de Amsterdam defendeu, em entrevista a este pesquisador, a especificidade dos sons da capital holandesa, a partir do modo como sinos de igrejas e tantas outras manifestações sonoras reverberam pelas ruas de determinadas larguras, margeadas por todos os canais, em contato com os materiais de construção dos prédios antigos. Muita gente sensata defende que há uma luz holandesa ${ }^{11}$, um futebol holandês, cerveja holandesa. Há sons?

Dentro de uma série de gravações de sons em Glasgow, o que há neles que se pode dizer que contenha especificidades locais? 0 modo como os passos reverberam nas amplas e vazias ruas no bairro onde se localizava o hotel? 0 burburinho dos pubs? A voz e o violão dos numerosos cantores de rua, cantando pop britânico com sotaque escocês? Dentro da complexidade das manifestações sonoras de cada espaço urbano, 0 que se pode dizer que seja próprio de cada lugar, e, para tornar menor um questionamento tão amplo, como pode 0 cinema representar as possíveis especificidades?

\section{Referências}

ALTMAN, Rick. Silent film sound. New York: Columbia University Press, 2004.

CHION, Michel. Audio-vision: sound on screen. New York: Columbia University Press, 1994.

Film: A Sound Art. New York: Columbia

University Press, 2009.

COSTA, Fernando Morais da. Pode-se dizer que há algo como um hiperrealismo sonoro no cinema argentino?

Ciberlegenda - Revista do Programa de Pós-

Graduação em Comunicação da Universidade Federal Fluminense, Niterói, v. 1, n. 24, p. 84-90, 2011.

FISCHER, Lucy. Enthusiasm: From Kino-Eye to Radio-Eye. In: WEIS, Elisabeth, BELTON, John (Org.). Film Sound: theory and practice. New York: Columbia University Press, 1985. p. 247-264.

LOPES, Denílson. Paisagens Transculturais. In: MACHADO, Rubens; SOARES, Rosana de Lima; ARAUJO, Luciana Correa de. (Org.). Estudos de Cinema Socine. São Paulo: Annablume, 2007. p. 69-76.

MIRANDA, Suzana Reck. Duas vozes para o som no cinema; Tati e Bresson. In: ADES, Eduardo et al. (Org).

Catálogo da mostra cinematográfica 0 som no cinema. Rio de Janeiro: Caixa Cultural, 2008.

. Vozes polifônicas e escutas musicais: a

articulação da banda sonora em François Girard. In: MACHAD0, Rubens; SOARES, Rosana de Lima; ARAUJO, Luciana Correa de. (Org.). Estudos de Cinema Socine. São Paulo: Annablume, 2007. p. 41-48.

PRYSTHON, Ângela. Metrópoles latino-americanas no

Hipótese apresentada, por exemplo, no documentário Dutch Light, no qual historiadores de arte como Ernst van de Wetering defendem que a falta de relevo na paisagem rural em conjunto com a refração da luz pelos numerosos espelhos d'água acabam por produzir uma luminosidade específica daquele país. 
cinema contemporâneo. In: (Org.) Imagens

da cidade: espaços urbanos na comunicação e cultura contemporâneasPorto Alegre: Sulina, 2006. p. 254-269.

SCHAFER, R. Murray. A afinação do mundo: uma exploração pela história passada e pelo atual estado do mais negligenciado aspecto do nosso ambiente: a paisagem sonora. São Paulo: UNESP, 2003.

. 0 ouvido pensante. São Paulo: UNESP, 1997.

\section{Filmes citados}

AS FÉRIAS do senhor HulotDireção: Jacques Tati. França: Dicina Film, Cady Films, Specta Films, 1953. (114 min.), mono, P\&B. 35mm. Título original: Les vacances de Monsieur Hulot.BERLIM, sinfonia de uma metrópole. Direção: Walter Ruttmann. Alemanha: Deutsche Vereins-Film: Les Productions Fox Europa, 1927. (65 min.), mudo, P\&B, 35mm. Título original: Berlin, die Sinfonie der Grossstadt.

DUTCH light. Direção: Pieter-Rim de Kroon. Holanda: De Kroon, Wissenraet \& Associes, 2003. (95 min.), son., color., 35mm. Título original: Hollands licht.

ENTUZIAZM. Direção: Dziga Vertov. URSS: Ukrainfilm, 1931. (67 min.), mono, P\&B, 35mm. Título original: Entuziazm - Simfonyia Donbassa.

HOMEDireção: Ursula Méier. Suíça, França, Bélgica: Box Productions/Archiple 35/Need Productions, 2008. (98 min.), color., 35mm.

MADAME Satã. Direção: Karim Aïnouz. Brasil/França: Videofilmes, Dominant 7, Lumière , ANO. (105 min.), color., $35 \mathrm{~mm}$.

MAP of the sounds of tokyoDireção: Isabel Coixet. Espanha: Mediapro/Versátil cinema, 2009. (98 min.), color., $35 \mathrm{~mm}$.

MEDIANERAS, Buenos Aires na era do amor virtual. Direção: Gustavo Taretto. Argentina, Espanha, Alemanha: Eddie Saeta/INCAA/Pandora
Filmproduktion, 2011. (95 min.), color., 35mm.

MELODIA do mundo. Direção:Walter Ruttmann. Alemanha: Tobis Filmkunst, 1929. (49 min.), mono, P\&B, 35mm. Título original: Melodie der Welt.

0 CÉU de Lisboa.Direção: Win Wenders. Alemanha/ Portugal: Madragoa Filmes, Road Movies

Filmproduktion, 1994. (100 min., color., 35mm. Título original: Lisbon Story.

RIEN que les heures. Direção: Alberto Cavalcanti. França: 1926. (45 min.), mudo, P\&B, 35mm.

RUÍD0 Direção: Marcelo Bertalmío. Uruguai/Argentina/ Espanha: Lavorágine Filmes/Zip Filmes , 2005. (90 min.), color., $35 \mathrm{~mm}$.

SÃ0 PAULO, a sinfonia da metrópole. Direção: Rodolfo Lustig e Adalberto Kemeny. Brasil: Rex Filmes, 1929. (90 min.), mudo, P\&B, 35mm.

THE CITY. Direção: Ralph Elton. Reino Unido: General Post Office Film Unit, 1939. (19 min.), mono, P\&B, $35 \mathrm{~mm}$.

UM HOMEM com uma câmera. Direção: Dziga Vertov. URSS: VUFKU, 1929. (68 min.), mudo, P\&B, 35mm. Título original: Chelovek s kino-apparatom

VALENTÍN. Direção: Alejandro Agresti. Argentina/ Holanda/Espanha/França/Itália: First Floor Pictures, De Productie, RWA, Patagonik Film Group, 2002. (86 min.), color., $35 \mathrm{~mm}$. 
Urban sounds and their hearing through cinema

\section{Abstract}

This paper aims to analyse how films can represent urban sound ambiences. Therefore, it takes a closer look at the so called "city sinfonies", films made between the late silent era and the early sound years. In a second section, it moves forward to contemporary cinema, analysing productions in which the representation of the city area plays a central part. In each of the films cited, and at this point it makes no difference to this analysis which period they come from, it is of our interest to think of the specific part of the cinematic representation given to sound, as far as it is possible to think about how listening to those films can lead the spectator towards a reflexion on how they relate to sounds that surround them in the urban space they live in.

\section{Keywords}

Sound. Cinema. City. Ambient Sound. Hearing.

\section{Sonidos urbanos y sus escuchas a través del cine}

\section{Resumen}

Este trabajo pretende analizar las posibilidades de representación de los ambientes sonoros urbanos por medio del cine. Para ello, nos detenemos, en una primera sección, a las llamadas "sinfonías de ciudades", películas producidas en el pasaje del cine mudo al cine sonoro. En un segundo momento, hacemos un puente con el cine contemporáneo, analizando las películas en las que la representación del espacio de determinadas ciudades es central para las respectivas tramas. En todas las películas analizadas, teniendo en cuenta que es indiferente para nosotros la época en la cual se las produjeron, nos interesa pensar la parte sonora de la representación, a la vez que podemos pensar cómo las escuchas de esas películas pueden provocar en el espectador una reflexión sobre el modo con el cual él se relaciona con los sonidos que lo circundan en el cotidiano urbano.

\section{Palabras Clave}

Sonido. Cine. Ciudad. Sonidos ambientes. Escucha. 


\section{Expediente}

A revista E-Compós é a publicação científica em formato eletrônico da Associação Nacional dos Programas de Pós-Graduação em Comunicação (Compós). Lançada em 2004, tem como principal finalidade difundir a produção acadêmica de pesquisadores da área de Comunicação, inseridos em instituições do Brasil e do exterior.

\section{E-COMPÓS I www.e-compos.org.br I E-ISSN 1808-2599}

Revista da Associação Nacional dos Programas

de Pós-Graduação em Comunicação.

Brasília, v.15, n.2, maio/ago. 2012.

A identificação das edições, a partir de 2008 ,

passa a ser volume anual com três números.

\section{CONSELHO EDITORIAL}

Afonso Albuquerque, Universidade Federal Fluminense, Brasil Alberto Carlos Augusto Klein, Universidade Estadual de Londrina, Brasil Álvaro Larangeira, Universidade Tuiuti do Paraná, Brasi André Luiz Martins Lemos, Universidade Federal da Bahia, Brasil Ângela Freire Prysthon, Universidade Federal de Pernambuco, Brasil Angela Cristina Salgueiro Marques, Faculdade Cásper Líbero (São Paulo), Brasil Antonio Roberto Chiachiri Filho, Faculdade Cásper Líbero, Brasil Arthur Autran Franco de Sá Neto, Universidade Federal de São Carlos, Brasil Benjamim Picado, Universidade Federal Fluminense, Brasil César Geraldo Guimarães, Universidade Federal de Minas Gerais, Brasil Cristiane Freitas Gutfreind, Pontifícia Universidade Católica do Rio Grande do Sul, Brasil

Denilson Lopes, Universidade Federal do Rio de Janeiro, Brasil Eduardo Peñuela Cañizal, Universidade Paulista, Brasi Eduardo Vicente, Universidade de São Paulo, Brasil Eneus Trindade, Universidade de São Paulo, Brasil Florence Dravet, Universidade Católica de Brasília, Brasil Gelson Santana, Universidade Anhembi/Morumbi, Brasil Gislene da Silva, Universidade Federal de Santa Catarina, Brasil Guillermo Orozco Gómez, Universidad de Guadalajara Gustavo Daudt Fischer, Universidade do Vale do Rio dos Sinos, Brasil Hector Ospina, Universidad de Manizales, Colômbia Herom Vargas, Universidade Municipal de São Caetano do Sul, Brasil Inês Vitorino, Universidade Federal do Ceará, Brasil Jay David Bolter, Georgia Institute of Technology Jeder Silveira Janotti Junior, Universidade Federal de Pernambuco, Brasil John DH Downing, University of Texas at Austin, Estados Unidos José Afonso da Silva Junior, Universidade Federal de Pernambuco, Brasil José Carlos Rodrigues, Pontifícia Universidade Católica do Rio de Janeiro, Brasi José Luiz Aidar Prado, Pontifícia Universidade Católica de São Paulo, Brasil Kelly Cristina de Souza Prudêncio, Universidade Federal do Paraná, Brasil. Laan Mendes Barros, Universidade Metodista de São Paulo, Brasil
Lance Strate, Fordham University, USA, Estados Unidos

Lorraine Leu, University of Bristol, Grã-Bretanha

Lucia Leão, Pontifícia Universidade Católica de São Paulo, Brasil

Malena Segura Contrera, Universidade Paulista, Brasil

Márcio de Vasconcellos Serelle, Pontifícia Universidade Católica de Minas Gerais, Brasil

Maria Aparecida Baccega, Universidade de São Paulo e Escola Superior de Propaganda e Marketing, Brasil

Maria Ataide Malcher, Universidade Federal do Pará, Brasi

Maria das Graças Pinto Coelho, Universidade Federal do Rio Grande do Norte, Brasil

Maria Immacolata Vassallo de Lopes, Universidade de São Paulo, Brasil Maria Luiza Martins de Mendonça, Universidade Federal de Goiás, Brasi Mauro de Souza Ventura, Universidade Estadual Paulista, Brasil Mauro Pereira Porto, Tulane University, Estados Unidos Mirna Feitoza Pereira, Universidade Federal do Amazonas, Brasil Nilda Aparecida Jacks, Universidade Federal do Rio Grande do Sul, Brasil Osvando J. de Morais, Universidade de Sorocaba, Brasil Potiguara Mendes Silveira Jr, Universidade Federal de Juiz de Fora, Brasil Renato Cordeiro Gomes, Pontifícia Universidade Católica do Rio de Janeiro, Brasil Robert K Logan, University of Toronto, Canadá

Ronaldo George Helal, Universidade do Estado do Rio de Janeiro, Brasil Rose Melo Rocha, Escola Superior de Propaganda e Marketing, Brasil Rossana Reguillo, Instituto de Estudos Superiores do Ocidente, Mexico Rousiley Celi Moreira Maia, Universidade Federal de Minas Gerais, Brasil Sebastião Guilherme Albano da Costa, Universidade Federal do Rio Grande do Norte, Brasil

Simone Maria Andrade Pereira de Sá, Universidade Federal Fluminense, Brasil Tiago Quiroga Fausto Neto, Universidade de Brasília, Brasil Suzete Venturelli, Universidade de Brasília, Brasil Valerio Fuenzalida Fernández, Puc-Chile, Chile Veneza Mayora Ronsini, Universidade Federal de Santa Maria, Brasil Vera Regina Veiga França, Universidade Federal de Minas Gerais, Brasil

\section{COMISSÃO EDITORIAL}

Adriana Braga I Pontifícia Universidade Católica do Rio de Janeiro, Brasil

Felipe Costa Trotta I Universidade Federal Fluminense, Brasi

CONSULTORES AD HOC

Adriana Amaral, Universidade do Vale do Rio dos Sinos, Brasil

Ana Carolina Escosteguy, Pontifícia Universidade Católica do Rio Grande do Sul, Brasi Claudia Azevedo, Universidade Federal do Estado do Rio de Janeiro, Brasil Gisela Castro, Escola Superior de Propaganda e Marketing, Brasil Luis Queiroz, Universidade Federal da Paraíba, Brasil Rodrigo Carreiro, Universidade Federal de Pernambuco, Brasil EDIÇÃO DE TEXTO E RESUMOS I Susane Barros SECRETÁRIA EXECUTIVA I Juliana Depiné EDITORAÇÃO ELETRÔNICA I Roka Estúdio TRADUÇÃo I Sieni Campos
COMPÓS I www.compos.org.br

Associação Nacional dos Programas de Pós-Graduação em Comunicação

Presidente

Julio Pinto

Pontifícia Universidade Católica de Minas Gerais, Brasil juliopinto@pucminas.br

Vice-presidente

Itania Maria Mota Gomes

Universidade Federal da Bahia, Brasil

itania@ufba.br

Secretária-Geral

Inês Vitorino

Universidade Federal do Ceará, Brasil

inesvic@gmail.com 